\title{
Tolerância de Cinco Cultivares de mandioca (Manihot esculenta) A HERBICIDAS $^{1}$
}

\author{
Tolerance of Five Cassava (Manihot esculenta) Cultivars to Herbicides
}

\author{
OLIVEIRA JR., R.S. ${ }^{2}$, CONSTANTIN, J. ${ }^{2}$, HERNANDES, A.I.F.M. ${ }^{3}$, INOUE, M.H. ${ }^{3}$, \\ MARCHIORI JR., O. ${ }^{3}$ e RAMIRES, A.C. ${ }^{3}$
}

\begin{abstract}
RESUMO - Este trabalho de pesquisa foi conduzido no município de Araruna-PR, com o objetivo de avaliar a tolerância dos cultivares de mandioca Espeto, Mico, Fécula Branca, IAC-14 e Fibra a diferentes herbicidas. Os tratamentos avaliados foram: testemunha sem herbicida, metribuzin $\left(0,49 \mathrm{~kg}\right.$ i.a. ha $\left.{ }^{-1}\right)$, clomazone $\left(1,00 \mathrm{~kg}\right.$ i.a. ha $\left.{ }^{-1}\right)$, mistura formulada de ametryne + clomazone 2,50 kg i.a. ha $\left.{ }^{-1}\right)$ e ametryne + trifluralin $\left(1,50+1,80 \mathrm{~kg}\right.$ i.a. ha $\left.{ }^{-1}\right)$. Todos os tratamentos foram mantidos capinados durante o ciclo da cultura. Utilizou-se o esquema fatorial $\left(5^{2}\right)$, e delineamento experimental em blocos casualizados. Foram avaliados sintomas de fitotoxicidade, estande, altura e produtividade. O tratamento com ametryne + trifluralin foi o mais seletivo à cultura, e apenas a mistura formulada de ametryne + clomazone, nos cultivares Mico e Fécula, causou sintomas visuais de fitotoxicidade aos 51 dias após o plantio. Nenhum dos tratamentos químicos afetou o estande ou o crescimento da cultura. As maiores produtividades de raízes foram obtidas com os cultivares Fécula Branca e IAC-14.
\end{abstract}

Palavras-chave: seletividade, fitotoxicidade, metribuzin, ametryne, trifluralin, clomazone.

\begin{abstract}
This work was carried out at Araruna, PR - Brazil, to evaluate the tolerance of five cassava cultivars (Espeto, Mico, Fécula Branca, IAC-14, and Fibra) to different herbicides. Treatments evaluated were check (no herbicide), metribuzin $\left(0.49 \mathrm{~kg}\right.$ a.i. ha ${ }^{-1}$ ), clomazone $\left(1.00 \mathrm{~kg}\right.$ a.i. $\left.\mathrm{ha}^{-1}\right)$, formulated mixture of ametryn + clomazone $\left(2.50 \mathrm{~kg}\right.$ a.i. ha $\left.\mathrm{g}^{-1}\right)$ and ametryn + trifluralin $\left(1.50+1.80 \mathrm{~kg}\right.$ a.i. $\left.\mathrm{ha}^{-1}\right)$. All treatments were maintained weed free during the entire crop cycle. The experiment was arranged in a factorial scheme $\left(5^{2}\right)$, randomized block design. Tolerance was evaluated based on phytotoxicity symptoms, crop stand, height and yield. Ametryn + trifluralin was the most selective treatment applied to cassava and only the formulated mixture of ametryn + clomazone caused visual symptoms of injury in the Mico and Fécula cultivars, at 51 days after planting. No chemical treatments affected cassava stand or height. The highest root yields were achieved by the cultivars Fécula Branca and IAC-14.
\end{abstract}

Key words: selectivity, phytotoxicity, metribuzin, ametryn, trifluralin, clomazone.

\section{INTRODUÇÃO}

A mandioca (Manihot esculenta) é cultura tradicional nas regiões tropicais, produtora de carboidratos e de considerável importância na alimentação humana e animal (Andrade, 1989). Esta planta é uma importante fonte alimentícia nos trópicos, com destaque para sua alta capacidade de produção e adaptação às condições climáticas e culturais diversas. Tanto suas folhas quanto as raízes são úteis como fonte de alimento humano e animal. $\mathrm{O}$ teor de proteína nas folhas é elevado, sendo sua raiz largamente empregada na produção industrial do amido e na de álcool anidro (Lorenzi \& Dias, 1993).

1 Recebido para publicação em 5/9/2000 e na forma revisada em 6/12/2000.

2 Prof. Adjunto do Dep. de Agronomia da Universidade Estadual de Maringá. Av. Colombo 5790, 87020-900 Maringá-PR;

${ }^{3}$ Acadêmico(a) do Curso de Agronomia da Universidade Estadual de Maringá. 
Levando em conta que o ciclo da mandioca pode atingir até dois anos, percebe-se que o problema de manejo de plantas daninhas é bastante complexo, pois ocorrem diversos fluxos de infestação durante o ciclo da lavoura (Deuber, 1997), os quais podem reduzir drasticamente a produção de mandioca, em razão das interferências que impõem (competição, alelopatia, hospedeira de pragas e doenças, etc.).

No Estado do Paraná, um dos maiores problemas que a exploração da mandioca enfrenta é o reduzido número de herbicidas registrados para uso na cultura, bem como a carência de estudos relacionados à seletividade de novos herbicidas para a cultura. Até o ano de 1998, apenas o metribuzin encontrava-se registrado para uso na cultura (Rodrigues \& Almeida, 1998). No ano de 1999, em virtude do aumento na demanda de utilização, foi concedido o cadastro estadual para o clomazone, e espera-se que novos herbicidas venham a ser registrados a médio prazo. Resultados preliminares indicaram que, além de metribuzin e clomazone, as misturas ametryne+trifluralin e ametryne+ clomazone possuem bom potencial para serem utilizadas na cultura. Pouco se sabe, no entanto, a respeito da seletividade dessas possiveis novas alternativas para os cultivares de mandioca mais cultivados atualmente no Estado.

Diversos trabalhos evidenciaram diferenças intervarietais de sensibilidade a herbicidas em várias culturas. Damião Filho et al. (1996) compararam o comportamento de nove híbridos de milho em relação à sensibilidade ao nicosulfuron, concluindo que em pelo menos um dos híbridos estudados houve redução da produtividade. Land et al. (1999) demonstraram que o índice de resistência de plantas de milho ao trifluralin é uma característica genética e que descendentes oriundos do cruzamento entre dois híbridos resistentes têm tolerância ao herbicida ainda maior que suas progênies. Wychen et al. (1999) avaliaram a tolerância de híbridos de milho doce ao isoxaflutole, concluindo que além da variabilidade de suscetibilidade inerente aos híbridos, a tolerância variava em função do tipo de solo em que o plantio era feito. Wilson (1999) avaliou nove cultivares de beterraba utilizando herbicidas aplicados em pós-emergência e evidenciou que a tolerância variava entre cultivares e até mesmo entre anos de plantio, dentro do mesmo cultivar. Rolim et al. (2000) detectaram diferenças significativas quanto à sensibilidade inicial de alguns cultivares de cana-de-açúcar (Saccharum officinarum) aos diversos herbicidas aplicados em pré-emergência. Em geral, o comportamento diferencial dos cultivares, com relação à tolerância aos herbicidas, é atribuído a fatores fisiológicos e ou edafoclimáticos.

Resultados obtidos anteriormente (Doll \& Piedrahita, 1974, 1976; Oliveira Jr., 1994; Oliveira Jr. et al., 1995) indicam que a resposta da mandioca à aplicação de herbicidas varia desde a total seletividade até o completo comprometimento da produção, por causa da toxicidade provocada à cultura. Em alguns casos, a variação na resposta da mandioca a herbicidas ocorre em função da dose aplicada (Alcântara \& Lima, 1982) ou do tipo de solo no qual o trabalho foi conduzido (Alcântara \& Souza, 1982).

Este trabalho teve por objetivo avaliar a tolerância de cinco dos principais cultivares de mandioca cultivados no Paraná a diferentes tratamentos de controle de plantas daninhas, visando atender às necessidades dos setores agrícola e industrial mandioqueiro das regiões norte e noroeste do Estado do Paraná.

\section{MATERIAL E MÉTODOS}

O experimento foi conduzido na Fazenda da Pinduca Indústria Alimentícia Ltda., localizada no município de Araruna, Estado do Paraná. A unidade de solo predominante na região é o Latossolo Vermelho distrófico, textura média; as características químicas e físicas de amostras deste solo encontram-se na Tabela 1.

Antes do plantio de mandioca, a área do experimento havia sido cultivada com aveia. Vinte dias antes do plantio (DAP), a aveia foi dessecada com glyphosate a $0,72 \mathrm{~kg}$ e.a. ha ${ }^{-1}$ e, sete dias antes do plantio, foi utilizado rolofaca na área, de modo que propiciasse cobertura morta para o solo. Por ocasião do plantio, procedeu-se apenas à abertura dos sulcos, como preparo de solo. O plantio foi efetuado em 26/10/ 1999, distribuindo-se as manivas manualmente, nos sulcos, na posição horizontal, a aproximadamente $10 \mathrm{~cm}$ de profundidade e cobrindo posteriormente com solo. O espaçamento 
utilizado foi de $0,90 \times 0,70 \mathrm{~m}$, e a primeira precipitação após o plantio ocorreu em $27 / 10$ / $1999(6,0 \mathrm{~mm})$. Os tratos culturais realizados foram aqueles normalmente empregados para a cultura na região, conforme Conceição (1979) e Lorenzi \& Dias (1993). A colheita foi realizada em 3/7/2000.

A aplicação dos tratamentos foi feita em duas épocas. Dois dias após o plantio fez-se a aplicação, em pré-emergência, de clomazone (1,00 $\left.\mathrm{kg} \mathrm{ha}^{-1}\right)$, metribuzin $\left(0,49 \mathrm{~kg} \mathrm{ha}^{-1}\right) \mathrm{e}$ ametryne+trifluralin $\left(1,50+1,80 \mathrm{~kg} \mathrm{ha}^{-1}\right)$. A mistura formulada ametryne+clomazone $\left(2,50 \mathrm{~kg} \mathrm{ha}^{-1}\right)$ foi aplicada aos $17 \mathrm{DAP}$, quando 5 a $10 \%$ das ramas de mandioca estavam brotadas. Além dos tratamentos com herbicidas, foi mantida uma parcela sem herbicida, capinada por todo o ciclo. Em ambas as aplicações o solo apresentava-se úmido, com umidade relativa do ar superior a $80 \%$, ventos moderados e temperatura de 20 a $23{ }^{\circ} \mathrm{C}$. Foi utilizado um pulverizador costal de pressão constante, à base de $\mathrm{CO}_{2}$, com bicos leque 110-SF-02, pressão de $2,0 \mathrm{kgf} \mathrm{cm}^{-2}$, o qual proporcionou volume de 200 litros de calda por hectare.

Foi adotado o delineamento experimental em blocos casualizados, com quatro repetições. Os tratamentos foram implantados num esquema fatorial que combinava cinco métodos de controle das plantas daninhas (clomazone, metribuzin, ametryne+trifluralin, ametryne+ clomazone e testemunha sem herbicida) com cinco cultivares de mandioca (Espeto, Mico, Fécula Branca, IAC-14 e Fibra). Todos os tratamentos foram mantidos limpos por meio de capinas manuais com enxada durante todo o ciclo da cultura, visando impedir que a interferência do mato prejudicasse as análises de seletividade. As características dos cultivares avaliados encontram-se na Tabela 2.

Tabela 1 - Características químicas e físicas de amostras de solo oriundas da área do experimento de campo. Araruna-PR - 1999/ 2000

\begin{tabular}{|c|c|c|c|c|c|c|c|c|c|c|c|}
\hline \multicolumn{2}{|c|}{$\mathrm{pH}$} & $\mathrm{Al}^{3+}$ & $\mathrm{H}^{+}+\mathrm{Al}^{3+}$ & $\mathrm{Ca}^{+}+\mathrm{Mg}^{2+}$ & $\mathrm{Ca}^{2+}$ & $\mathrm{K}^{+}$ & \multirow{2}{*}{$\begin{array}{c}\mathrm{P} \\
\mathrm{mg} \mathrm{dm}{ }^{-3}\end{array}$} & \multirow{2}{*}{$\begin{array}{c}\mathrm{C} \\
\mathrm{g} \mathrm{dm}^{-3}\end{array}$} & Areia & Silte & Argila \\
\hline $\mathrm{CaCl}_{2}$ & $\mathrm{H}_{2} \mathrm{O}$ & \multicolumn{5}{|c|}{------ $\mathrm{cmol}_{\mathrm{c}} \mathrm{dm}^{-3}$-- } & & & \multicolumn{3}{|c|}{----------- \% ----------- } \\
\hline 5,9 & 6,7 & 0,00 & 2,54 & 4,83 & 3,08 & 0,39 & 6,00 & 9,18 & 70 & 01 & 29 \\
\hline
\end{tabular}

Tabela 2 - Descrição dos cultivares utilizados no experimento. Araruna-PR - 1999/2000

\begin{tabular}{|c|c|c|c|c|c|}
\hline \multirow{2}{*}{ Caracteres Fenotípicos } & \multicolumn{5}{|c|}{ Cultivares } \\
\hline & Espeto & Mico & Fécula Branca & IAC 14 & Fibra \\
\hline Lóbulo da folha & Linear, sinuoso & Obovado, liso & Obovado, liso & Obovado, liso & Linear, pouco sinuoso \\
\hline Coloração do pecíolo & Vinho-clara & Vermelha & Vermelha & Vinho & Vermelha \\
\hline Coloração da brotação nova & Verde-arroxeada & Verde-arroxeada & Verde-arroxeada & Verde-arroxeada & Verde \\
\hline Ramificação & Tricotômica & Tricotômica & Tricotômica & Tricotômica & Tricotômica \\
\hline Florescimento & Floresce & Floresce & Floresce & Floresce & Floresce \\
\hline Coloração da rama madura & Cinza-prateada & Marrom-clara & Cinza-prateada & Cinza-prateada & Cinza-prateada \\
\hline Suscetibilidade à bacteriose & Alta & Baixa & Baixa & Baixa & Alta \\
\hline Espessura da película suberosa & Fina,lisa & Grossa, rugosa & Fina, lisa & Grossa, rugosa & Fina, lisa \\
\hline Coloração da película suberosa & Creme & Marrom-escura & Clara & Marrom-escura & Creme \\
\hline Coloração da camada cortical & Creme & Creme & Creme & Creme & Creme \\
\hline Coloração da polpa & Branca & Branca & Branca & Branca & Branca \\
\hline Pedúnculo & Médio & Curto & Curto & Curto & Curto \\
\hline Cintas & Ausentes & Ausentes & Ausentes & Ausentes & Ausentes \\
\hline
\end{tabular}

Fonte: Adaptado de Vidigal Filho et al. (2000). 
A área das parcelas era de 5,40 x 6,00 m, adotando-se como área útil $1,80 \times 4,00 \mathrm{~m}$ centrais. O efeito dos métodos de manejo das plantas daninhas sobre a cultura da mandioca foi estimado por meio da avaliação de características relacionadas ao aparecimento de sintomas visuais de fitotoxicidade (Escala EWRC, adaptada por Azzi \& Fernandes, 1968, aos 24, 37 e 51 DAP), estande (no de brotações na área útil da parcela aos 24,37 e 51 DAP), crescimento (altura de 10 plantas/parcela aos 73 DAP) e produtividade (colheita da área útil da parcela).

Os dados foram submetidos à análise de variância, desdobrando-se todas as interações possíveis. As médias foram comparadas pelo teste de Tukey a 5\% de probabilidade.

\section{RESULTADOS E DICUSSÃO}

As notas médias de fitotoxicidade aos 24, 37 e 51 DAP (Escala EWRC) ocasionada pelos herbicidas são apresentadas na Tabela 3. Verifica-se, para todos os cultivares, que o tratamento ametryne+clomazone causou os sintomas de injúrias mais evidentes, os quais consistiram em encarquilhamento progressivo dos ponteiros até os 37 DAP. Entretanto, a partir dessa data, à medida que novas folhas surgiam, os sintomas desapareciam e o crescimento normal era restabelecido. Para os demais tratamentos com herbicidas, os sintomas de fitotoxicidade foram de intensidade semelhante ou inferior aos observados para ametryne+clomazone. Exceto para ametryne+ clomazone nos cultivares Mico e Fécula, nenhum sinal visual de toxicidade foi observado aos 51 DAP. De modo geral, o cultivar Espeto foi o mais tolerante aos herbicidas utilizados, evidenciando o menor nível de injúrias. Podese observar também que o tratamento com ametryne+trifluralin provocou os menores sintomas iniciais e de persistência de fitotoxicidade, proporcionando, portanto, maior seletividade para a cultura. Em trabalhos realizados anteriormente encontraram-se resultados semelhantes, isto é, ametryne e trifluralin foram os herbicidas mais seletivos para a mandioca (Oliveira Jr., 1994; Fornarolli et al., 2000).

Em relação ao estande da cultura, observase que não houve diferenças significativas entre os métodos de controle, na primeira avaliação (24 DAP - Tabela 4), embora fosse observada certa desuniformidade na emergência da parte aérea das plantas de mandioca. À medida que o tempo passou e os coeficientes de variação diminuíram (da Tabela 4 para a Tabela 6), ficou evidente que praticamente nenhum dos herbicidas ou nenhuma das combinações utilizadas afetou o estande da cultura, o que ocorreu de forma mais consistente para a testemunha sem herbicida no cultivar Fécula Branca. Supõe-se que pode ter ocorrido maior dano às plantas de mandioca durante a fase de emergência, quando as plantas novas podem ser acidentalmente danificadas pelas capinas. Isto porque, durante o período de avaliação dos tratamentos, as testemunhas sem herbicida receberam pelo menos três capinas manuais a mais do que as parcelas tratadas com herbicidas.

Tabela 3 - Toxicidade visual (Escala EWRC ${ }^{1 /}$ ), aos 24, 37 e 51 DAP, observada em cinco cultivares de mandioca submetidos a diversos tratamentos de controle de plantas daninhas. Araruna-PR - 1999/2000

\begin{tabular}{|c|c|c|c|c|c|c|c|c|c|c|c|c|c|c|c|c|}
\hline \multirow{3}{*}{ Tratamentos de controle } & \multirow{3}{*}{$\begin{array}{l}\text { Dose i.a. } \\
\left(\mathrm{kg} \mathrm{ha}^{-1}\right)\end{array}$} & \multicolumn{15}{|c|}{ Cultivares } \\
\hline & & \multicolumn{3}{|c|}{ Espeto } & \multicolumn{3}{|c|}{ Mico } & \multicolumn{3}{|c|}{ Fécula Branca } & \multicolumn{3}{|c|}{ IAC-14 } & \multicolumn{3}{|c|}{ Fibra } \\
\hline & & 24 & 37 & 51 & 24 & 37 & 51 & 24 & 37 & 51 & 24 & 37 & 51 & 24 & 37 & 51 \\
\hline 1. Testemunha sem herbicida & - & 1,0 & 1,0 & 1,0 & 1,0 & 1,0 & 1,0 & 1,0 & 1,0 & 1,0 & 1,0 & 1,0 & 1,0 & 1,0 & 1,0 & 1,0 \\
\hline 2. Metribuzin & 0,49 & 2,5 & 1,5 & 1,0 & 2,0 & 1,0 & 1,0 & 1,0 & 1,5 & 1,0 & 2,0 & 4,5 & 1,0 & 1,5 & 4,5 & 1,0 \\
\hline 3. Clomazone & 1,00 & 1,5 & 1,5 & 1,0 & 1,5 & 1,0 & 1,0 & 2,5 & 4,5 & 1,0 & 3,0 & 4,0 & 1,0 & 2,5 & 4,5 & 1,0 \\
\hline 4. Ametryne+clomazone & 2,50 & 3,0 & 1,5 & 1,0 & 3,0 & 5,0 & 2,0 & 2,5 & 4,5 & 3,0 & 3,0 & 4,0 & 1,0 & 2,5 & 4,5 & 1,0 \\
\hline 5. Ametryne+trifluralin & $1,50+1,80$ & 1,5 & 1,0 & 1,0 & 1,5 & 1,0 & 1,0 & 1,0 & 1,0 & 1,0 & 1,5 & 1,0 & 1,0 & 1,5 & 1,0 & 1,0 \\
\hline
\end{tabular}

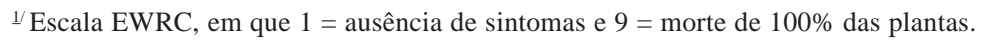


Tabela 4 - Resultados médios do estande (mil plantas/ha), aos 24 DAP, observados em cinco cultivares de mandioca submetidos a diversos tratamentos de controle de plantas daninhas. Araruna-PR - 1999/2000

\begin{tabular}{|l|c|c|c|c|c|c|c|}
\hline \multirow{2}{*}{ Tratamentos de controle } & \multirow{2}{*}{$\begin{array}{c}\text { Dose i.a. } \\
\left(\mathrm{kg} \mathrm{ha}^{-1}\right)\end{array}$} & \multicolumn{5}{|c|}{ Cultivares } & \multirow{2}{*}{ Médias } \\
\cline { 3 - 8 } & & Espeto & Mico & Fécula Branca & IAC-14 & Fibra & \\
\hline 1. Testemunha sem herbicida & - & $6,60 \mathrm{ABa}$ & $6,95 \mathrm{ABa}$ & $3,13 \mathrm{Ba}$ & $6,60 \mathrm{ABa}$ & $8,34 \mathrm{Aa}$ & $6,32 \mathrm{~b}$ \\
2. Metribuzin & 0,49 & $11,12 \mathrm{Aa}$ & $8,69 \mathrm{ABa}$ & $4,87 \mathrm{Ba}$ & $11,12 \mathrm{Aa}$ & $8,34 \mathrm{ABa}$ & $8,83 \mathrm{a}$ \\
3. Clomazone & 1,00 & $8,69 \mathrm{Aa}$ & $7,30 \mathrm{Aa}$ & $5,21 \mathrm{Aa}$ & $7,30 \mathrm{Aa}$ & $6,95 \mathrm{Aa}$ & $7,09 \mathrm{~b}$ \\
4. Ametryne+clomazone & 2,50 & $11,12 \mathrm{Aa}$ & $7,64 \mathrm{ABa}$ & $3,13 \mathrm{Ba}$ & $10,43 \mathrm{Aa}$ & $8,69 \mathrm{Aa}$ & $8,20 \mathrm{~b}$ \\
5. Ametryne+trifluralin & $1,50+1,80$ & $8,34 \mathrm{Aa}$ & $7,64 \mathrm{ABa}$ & $3,13 \mathrm{Ba}$ & $9,38 \mathrm{Aa}$ & $8,34 \mathrm{Aa}$ & $7,37 \mathrm{~b}$ \\
\hline \multicolumn{1}{|c|}{ Médias } & & $8,34 \mathrm{~A}$ & $7,64 \mathrm{~A}$ & $3,89 \mathrm{~B}$ & $8,97 \mathrm{~A}$ & $8,13 \mathrm{~A}$ & \\
\hline
\end{tabular}

As médias seguidas por uma mesma letra minúscula, na coluna, e maiúscula, na linha, não diferem a 5\% de probabilidade, pelo teste de Tukey. $\mathrm{CV}=33,96 \%$.

Tabela 5 - Resultados médios do estande (mil plantas/ha), aos 37 DAP, observados em cinco cultivares de mandioca submetidos a diversos tratamentos de controle de plantas daninhas. Araruna-PR - 1999/2000

\begin{tabular}{|l|c|c|c|c|c|c|c|}
\hline \multirow{2}{*}{ Tratamentos de controle } & \multirow{2}{*}{$\begin{array}{l}\text { Dose i.a. } \\
\left(\mathrm{kg} \mathrm{ha}^{-1}\right)\end{array}$} & \multicolumn{7}{|c|}{ Cultivares } & \multirow{2}{*}{ Médias } \\
\cline { 3 - 7 } & & Espeto & Mico & Fécula Branca & IAC-14 & Fibra & \\
\hline 1. Testemunha sem herbicida & - & $12,16 \mathrm{Aa}$ & $10,08 \mathrm{Aa}$ & $7,99 \mathrm{Ab}$ & $10,08 \mathrm{Aa}$ & $9,38 \mathrm{Ab}$ & $9,94 \mathrm{~b}$ \\
2. Metribuzin & 0,49 & $13,55 \mathrm{Aa}$ & $12,16 \mathrm{Aa}$ & $12,51 \mathrm{Aa}$ & $13,21 \mathrm{Aa}$ & $12,16 \mathrm{Aab}$ & $12,72 \mathrm{a}$ \\
3. Clomazone & 1,00 & $12,51 \mathrm{Aa}$ & $11,82 \mathrm{Aa}$ & $9,04 \mathrm{Aab}$ & $11,82 \mathrm{Aa}$ & $11,47 \mathrm{Aab}$ & $11,33 \mathrm{ab}$ \\
4. Ametryne+clomazone & 2,50 & $13,55 \mathrm{Aa}$ & $11,12 \mathrm{Aa}$ & $12,51 \mathrm{Aa}$ & $11,82 \mathrm{Aa}$ & $14,25 \mathrm{Aa}$ & $12,65 \mathrm{a}$ \\
5. Ametryne+trifluralin & $1,50+1,80$ & $11,12 \mathrm{Aa}$ & $10,77 \mathrm{Aa}$ & $10,77 \mathrm{Aab}$ & $13,55 \mathrm{Aa}$ & $11,47 \mathrm{Aab}$ & $11,54 \mathrm{ab}$ \\
\hline \multicolumn{1}{|c}{ Médias } & & $12,58 \mathrm{~A}$ & $11,19 \mathrm{AB}$ & $10,56 \mathrm{~B}$ & $12,09 \mathrm{AB}$ & $11,75 \mathrm{AB}$ & \\
\hline
\end{tabular}

As médias seguidas por uma mesma letra minúscula, na coluna, e maiúscula, na linha, não diferem a 5\% de probabilidade, pelo teste de Tukey. $\mathrm{CV}=18,18 \%$.

Tabela 6 - Resultados médios do estande (mil plantas/ha), aos 51 DAP, observados em cinco cultivares de mandioca submetidos a diversos tratamentos de controle de plantas. Araruna-PR - 1999/2000

\begin{tabular}{|l|c|c|c|c|c|c|c|}
\hline \multirow{2}{*}{ Tratamentos de controle } & \multirow{2}{*}{$\begin{array}{c}\text { Dose i.a. } \\
\left(\mathrm{kg} \mathrm{ha}^{-1}\right)\end{array}$} & \multicolumn{5}{|c|}{ Cultivares } & \multirow{2}{*}{ Médias } \\
\cline { 3 - 8 } & & Espeto & Mico & Fécula Branca & IAC-14 & \multicolumn{2}{|c|}{ Fibra } \\
\hline 1. Testemunha sem herbicida & - & $12,16 \mathrm{Aa}$ & $12,86 \mathrm{Aa}$ & $10,43 \mathrm{Ab}$ & $9,73 \mathrm{Aa}$ & $13,21 \mathrm{Aa}$ & $11,68 \mathrm{~b}$ \\
2. Metribuzin & 0,49 & $13,55 \mathrm{Aa}$ & $13,90 \mathrm{Aa}$ & $13,55 \mathrm{Aab}$ & $12,16 \mathrm{Aa}$ & $12,51 \mathrm{Aa}$ & $13,14 \mathrm{ab}$ \\
3. Clomazone & 1,00 & $13,90 \mathrm{Aa}$ & $12,51 \mathrm{Aa}$ & $11,82 \mathrm{Aab}$ & $12,16 \mathrm{Aa}$ & $13,90 \mathrm{Aa}$ & $12,86 \mathrm{ab}$ \\
4. Ametryne+clomazone & 2,50 & $14,60 \mathrm{Aa}$ & $13,21 \mathrm{Aa}$ & $14,25 \mathrm{Aa}$ & $12,51 \mathrm{Aa}$ & $14,60 \mathrm{Aa}$ & $13,83 \mathrm{a}$ \\
5. Ametryne+trifluralin & $1,50+1,80$ & $13,55 \mathrm{Aa}$ & $13,21 \mathrm{Aa}$ & $12,85 \mathrm{Aab}$ & $12,85 \mathrm{Aa}$ & $12,85 \mathrm{Aa}$ & $13,07 \mathrm{ab}$ \\
\hline \multicolumn{1}{|c}{ Médias } & & $13,55 \mathrm{~A}$ & $13,14 \mathrm{AB}$ & $12,58 \mathrm{AB}$ & $11,88 \mathrm{~B}$ & $13,41 \mathrm{AB}$ & \\
\hline
\end{tabular}

As médias seguidas por uma mesma letra minúscula, na coluna, e maiúscula, na linha, não diferem a 5\% de probabilidade, pelo teste de Tukey. $\mathrm{CV}=13,87 \%$. 
A Tabela 7 apresenta o desenvolvimento da cultura, demonstrando que nenhum tratamento químico afetou a altura de plantas aos 73 DAP, em relação à testemunha sem herbicida. A única diferença significativa observada foi em ametryne+clomazone e metribuzin, no cultivar Fécula Branca, que apresentaram portes mais elevados que a testemunha. Esse fato indica que a utilização de ametryne+ clomazone, mesmo causando certa fitotoxicidade inicial à cultura, não afeta negativamente o crescimento posterior dos cultivares avaliados. O cultivar IAC-14, no tratamento ametryne+clomazone, apresentou menor altura em relação ao melhor tratamento (metribuzin $\left.0,49 \mathrm{~kg} \mathrm{ha}^{-1}\right)$, não sendo afetado negativamente em relação à testemunha sem herbicidas.

Na Tabela 8 estão dispostos os resultados de produtividade de raízes dos cinco cultivares avaliados. Os resultados evidenciaram que apenas o cultivar IAC- 14 foi afetado pelo tratamento com ametryne+clomazone. No entanto, este tratamento não provocou decréscimo na produtividade de nenhum dos demais cultivares, nem na média de produtividade de todas os cultivares. Ao comparar as produtividades dos cultivares, dentro de cada tratamento de controle de plantas daninhas, observase que não são evidenciadas diferenças entre os cultivares na testemunha sem herbicida, ao passo que, nos tratamentos químicos, o cultivar Fécula Branca proporcionou produtividades sempre semelhantes ou superiores aos demais. Este cultivar também foi o que se mostrou mais produtivo na média dos três anos de trabalho conduzido por Vidigal Filho et al. (2000), que avaliaram nove cultivares na mesma região onde o experimento foi conduzido. Segundo estes autores, este cultivar pode ser recomendado para cultivo, na região de Araruna, por apresentar resistência à bacteriose e maior produtividade de raizes tuberosas. Por sua vez, o cultivar Fibra é o mais suscetível à bacteriose, o que pode ter contribuído para que ele fosse o menos produtivo neste experimento. De maneira geral, a ordem de produtividade para os cultivares foi Fécula Branca $\geq$ IAC-14 $>$ Espeto $=$ Mico $>$ Fibra .

Tabela 7 - Resultados médios da altura $(\mathrm{cm})$ de plantas de mandioca, aos 73 DAP, observados em cinco cultivares de mandioca submetidos a diversos tratamentos de controle de plantas daninhas. Araruna-PR - 1999/2000

\begin{tabular}{|c|c|c|c|c|c|c|c|}
\hline \multirow{2}{*}{ Tratamentos de controle } & \multirow{2}{*}{$\begin{array}{l}\text { Dose i.a. } \\
\left(\mathrm{kg} \mathrm{ha}^{-1}\right)\end{array}$} & \multicolumn{5}{|c|}{ Cultivares } & \multirow{2}{*}{ Médias } \\
\hline & & Espeto & Mico & Fécula Branca & IAC-14 & Fibra & \\
\hline 1. Testemunha sem herbicida & - & $11,17 \mathrm{Aa}$ & $12,00 \mathrm{Aa}$ & $12,33 \mathrm{Ab}$ & $14,92 \mathrm{Aab}$ & $11,17 \mathrm{Aa}$ & $12,32 \mathrm{c}$ \\
\hline 2. Metribuzin & 0,49 & $14,92 \mathrm{ABa}$ & $14,33 \mathrm{Ba}$ & $18,33 \mathrm{ABa}$ & $20,17 \mathrm{Aa}$ & $16,17 \mathrm{ABa}$ & $16,78 \mathrm{a}$ \\
\hline 3. Clomazone & 1,00 & $12,42 \mathrm{Aa}$ & $15,00 \mathrm{Aa}$ & $15,50 \mathrm{Aab}$ & $17,75 \mathrm{Aab}$ & $12,50 \mathrm{Aa}$ & $14,63 \mathrm{abc}$ \\
\hline 4. Ametryne+clomazone & 2,50 & $15,42 \mathrm{Aa}$ & $13,33 \mathrm{Aa}$ & $17,42 \mathrm{Aa}$ & $14,58 \mathrm{Ab}$ & $14,67 \mathrm{Aa}$ & $15,08 \mathrm{ab}$ \\
\hline 5. Ametryne+trifluralin & $1,50+1,80$ & $12,42 \mathrm{Aa}$ & $11,50 \mathrm{Aa}$ & $13,17 \mathrm{Aab}$ & $16,92 \mathrm{Aab}$ & $14,17 \mathrm{Aa}$ & $13,63 \mathrm{bc}$ \\
\hline Médias & & $13,27 \mathrm{~B}$ & $13,23 \mathrm{~B}$ & $15,35 \mathrm{AB}$ & $16,87 \mathrm{~A}$ & $13,73 \mathrm{~B}$ & \\
\hline
\end{tabular}

As médias seguidas por uma mesma letra minúscula, na coluna, e maiúscula, na linha, não diferem a 5\% de probabilidade, pelo teste de Tukey. $\mathrm{CV}=19,34 \%$.

Tabela 8 - Produtividade $\left(\mathrm{t} \mathrm{ha}^{-1}\right)$ observada em cinco cultivares de mandioca submetidos a diversos tratamentos de controle de plantas daninhas. Araruna-PR - 1999/2000

\begin{tabular}{|c|c|c|c|c|c|c|c|}
\hline \multirow{2}{*}{ Tratamentos de controle } & \multirow{2}{*}{$\begin{array}{l}\text { Dose i.a. } \\
\left(\mathrm{kg} \mathrm{ha}^{-1}\right)\end{array}$} & \multicolumn{5}{|c|}{ Cultivares } & \multirow{2}{*}{ Médias } \\
\hline & & Espeto & Mico & Fécula Branca & IAC-14 & Fibra & \\
\hline 1. Testemunha sem herbicida & - & 9,97 Aa & $14,58 \mathrm{Aa}$ & $16,87 \mathrm{Aa}$ & $18,44 \mathrm{Aab}$ & $10,87 \mathrm{Aa}$ & $14,15 \mathrm{a}$ \\
\hline 2. Metribuzin & 0,49 & $13,58 \mathrm{BCa}$ & $10,49 \mathrm{Ca}$ & $25,83 \mathrm{Aa}$ & $20,94 \mathrm{ABab}$ & $8,85 \mathrm{Ca}$ & $15,94 \mathrm{a}$ \\
\hline 3. Clomazone & 1,00 & $13,44 \mathrm{ABa}$ & $10,69 \mathrm{Ba}$ & $21,85 \mathrm{Aa}$ & 20,67 Aab & 7,74 Ba & $14,87 \mathrm{a}$ \\
\hline 4. Ametryne+clomazone & 2,50 & $18,19 \mathrm{ABa}$ & $16,39 \mathrm{ABa}$ & $24,63 \mathrm{Aa}$ & $13,44 \mathrm{Bb}$ & $9,44 \mathrm{Ba}$ & $16,42 \mathrm{a}$ \\
\hline 5. Ametryne+trifluralin & $1,50+1,80$ & $10,67 \mathrm{Ba}$ & $10,55 \mathrm{Ba}$ & $22,19 \mathrm{Aa}$ & $24,00 \mathrm{Aa}$ & $5,00 \mathrm{Ba}$ & 14,49 a \\
\hline Médias & & $13,17 \mathrm{~B}$ & $12,54 \mathrm{BC}$ & $22,28 \mathrm{~A}$ & $19,50 \mathrm{~A}$ & $8,39 \mathrm{C}$ & \\
\hline
\end{tabular}

As médias seguidas por uma mesma letra minúscula, na coluna, e maiúscula, na linha, não diferem a 5\% de probabilidade, pelo teste de Tukey. $\mathrm{CV}=31,28 \%$. 


\section{LITERATURA CITADA}

ALCÂNTARA, E.N.; LIMA, P.C. Efeito de doses de herbicida para a cultura da mandioca (Manihot esculenta Crantz). In: EPAMIG. Projeto Mandioca, relatório 76/ 79. Belo Horizonte: EPAMIG. 1982. p.130-135.

ALCÂNTARA, E.N.; SOUZA, I.F. Herbicidas na cultura da mandioca. In: EPAMIG. Projeto Mandioca, relatório 76/ 79. Belo Horizonte: EPAMIG. 1982. p.136-141.

ANDRADE, C.A.B. Efeitos de espaçamentos, idades de colheita e anos de plantio sobre algumas características de duas cultivares de mandioca (Manihot esculenta, Crantz). Lavras: ESAL: 1989. 63p. Dissertação (Mestrado em Fitotecnia) - Escola Superior de Agricultura de Lavras, 1989.

AZZI, G.M.; FERNANDES, J. Método de julgamento do efeito herbicida. In: CONGRESSO BRASILEIRO DE HERBICIDAS E ERVAS DANINHAS, 6, 1966, Sete Lagoas. Anais... Sete Lagoas: 1968. p.21-29.

CONCEIÇÃO, A.J. A mandioca. Cruz das Almas: UFBA/EMBAPA/BNB/BRASCAN NORDESTE, 1979. 382p.

DAMIÃO FILHO, C.F.; MÔRO, F.V.; TAVEIRA, L.R. Respostas de híbridos de milho ao nicosulfuron. I - Aspectos biológicos e da produção. Planta Daninha, v.14, n.1, p.3-13, 1996.

DEUBER, R. Ciência das plantas daninhas - Manejo. Campinas: Ed. do autor, 1997. 284p. v.2.

DOLL, J.D.; PIEDRAHITA, W. Margem de seletividade de vários herbicidas en yuca (Manihot esculenta Crantz). R. Comalfi, v.1, n.1, p.14-19, 1974.

DOLL, J.D.; PIEDRAHITA, W. Metodos de control de malezas en yuca. San José: Centro Internacional de Agricultura Tropical, 1976. 12p.

FORNAROLLI, D.A.; MORAES, V.J.; CAETANO, E.S., JESUS, F.A. Seletividade e eficácia de herbicidas na cultura da mandioca (Maninhot sativa). In: CONGRESSO BRASILEIRO DA CIÊNCIA DAS PLANTAS DANINHAS, 22, 2000, Foz do Iguaçu. Resumos... Londrina: SBCPD, 2000. p.258.
LAND, P.; FRASCAROLI, E.; GIULIANI, M.M. Genetic variability for resistence to trifluralin in Zea mays. Weed Sci., v.47, n.4, p.369-374, 1999.

LORENZI, J.O.; DIAS, C.A. Cultura da mandioca. Campinas: CATI, 1993. 41p. (Boletim Técnico, 211).

OLIVEIRA Jr., R.S. Seletividade e eficiência de trifluralin e diuron aplicados em diferentes formas na cultura da mandioca (Manihot esculenta Crantz). R. Unimar, v.16, n.2, p.317325, 1994.

OLIVEIRA Jr., R.S.; ZOTARELLI, L.; HIRAI, L.T. Seletividade e eficiência de controle de clethodim na fase inicial de desenvolvimento da cultura da mandioca. In: CONGRESSO BRASILEIRO DE HERBICIDAS E PLANTAS DANINHAS, 20, 1995, Florianópolis-SC. Resumos... Florianópolis: SBCPD, 1995. p.166-167.

RODRIGUES, B.N.; ALMEIDA, F.S. Guia de herbicidas, 4.ed. Londrina: 1998. 647p.

ROLIM, J.C.; JANEGITZ, I.; GARMS, M.A. Tolerância de variedades de cana-de-açúcar à herbicidas. 1 - Cana planta, solo arenoso, em pré-emergência. In: CONGRESSO BRASILEIRO DA CIÊNCIA DAS PLANTAS DANINHAS, 22, 2000, Foz do Iguaçu. Resumos... Londrina: SBCPD, 2000. p.258.

VIDIGAL FILHO, P.S.; PEQUENO, M.G.; SCAPIM, C.A.; GONÇALVES VIDIGAL, M.C.; MAIA, R.R.; SAGRILO, E.; SIMON, G.A.; LIMA, R.S. Avaliação de cultivares de mandioca na região noroeste do Paraná. Bragantia, v.59, n.1, p.69-75, 2000.

WILSON, R.G. Response of nine sugarbeet (Beta vulgaris) cultivars to postemergence herbicide applications. Weed Technol., v.13, n.1, p.2529, 1999.

WYCHEN, L.R.V.; HARVEY, R.G.; RABAEY, T.L.; BACH, D.J. Tolerance of sweet corn (Zea mays) hybrids to RPA 201772. Weed Technol., v.13, n.2, p.221-226, 1999. 